\title{
Flattening the Latent Growth Curve? Explaining Within-Person Changes in Employee Well-Being during the COVID-19 Pandemic
}

\author{
Jesse S. Michel ${ }^{1}$ (D) Michael A. Rotch ${ }^{1} \cdot$ Jack E. Carson $^{2} \cdot$ Nathan A. Bowling $^{3}$. \\ Nicole V. Shifrin ${ }^{1}$
}

Received: 23 October 2020 / Revised: 11 April 2021 / Accepted: 20 April 2021 /

Published online: 14 May 2021

(C) The Author(s), under exclusive licence to Springer Nature Switzerland AG 2021

\begin{abstract}
The COVID-19 pandemic represents one of the greatest global crises in modern history. In addition to recession and high unemployment, agencies such as the Centers for Disease Control and Prevention warn that stressors associated with a pandemic can cause increased strains, including difficulty concentrating, anxiety, and decreased mental health (CDC, 2020). Two general frameworks that explain these stressorstrain relationships over time include stress-reaction and adaptation models. Stressreaction models suggest that stressors, such as heightened job demands due to the pandemic, accumulate over time and thus prolonged exposure to these stressors results in both immediate and long-term strain; conversely, adaptation models suggest that people adapt to stressors over time, such that strains produced by ongoing stressors tend to dissipate. After controlling for county-level COVID-19 cases, we found that (a) workers in general exhibited decreasing cognitive weariness and psychological symptoms over time, providing support for the adaptation model; (b) on-site workers experienced increasing physical fatigue over time, supporting the stress-reaction model among those workers; and (c) engaging in recovery behaviors was associated with improvements in cognitive weariness and psychological symptoms for all workers. We also found that our Time 1 outcomes were significantly different than pre-pandemic norms, such that our participants displayed lower initial levels of job-related burnout and higher initial levels of psychological symptoms than pre-pandemic norms. Furthermore, supplemental qualitative data support our quantitative findings for recovery
\end{abstract}

Jesse S. Michel

jmichel@auburn.edu

1 Department of Psychological Sciences, Auburn University, 226 Thach Hall, Auburn,

AL 36849-5214, USA

2 Department of Management, Appalachian State University, Boone, NC, USA

3 Department of Psychology, Wright State University, Dayton, OH, USA 
behaviors. These findings have important implications for understanding workers' responses to the pandemic and they can help inform organizational practice.

Keywords COVID-19 · Burnout · Psychological health · Latent growth modeling · Longitudinal

The sudden and widespread emergence of COVID-19 has imposed drastic changes in how people around the world work and live. Since being declared a pandemic by the World Health Organization on March 11th, 2020, the spread of COVID-19 has disrupted the lives of workers across the globe. As of March 31, 2021, there have been 127 million confirmed cases of COVID-19 and more than 2.7 million COVIDrelated deaths (Dong et al., 2020; World Health Organization, 2020). Although the United States (US) has remained semi-operational during this state of emergency, organizations and their employees have had to respond to the crisis promptly and with little warning. This has resulted in record-breaking rates of unemployment in the US, with about 15\% of the country unemployed in April 2020 (Bureau of Labor Statistics, 2020). Although many were out of work, millions of other workers either continued performing their jobs as on-site workers or have transitioned to working remotely. Given the novelty of the current situation, it is unclear how workers' well-being is affected from the upheaval caused by the pandemic.

The present study aims to uncover how workers have responded to the pandemic. Specifically, we used latent growth modeling to examine within-person patterns of change in well-being over a 4-week period during the onset of the pandemic controlling for the possible effects of county-level COVID-19 infection rates. Considering that the Centers for Disease Control and Prevention warns that pandemic-related stressors lead to difficulty concentrating, anxiety, and decreased mental health (CDC, 2020), we focus on associated job-related burnout (e.g., cognitive weariness and emotional exhaustion) and general psychological symptoms. Furthermore, our analyses examined differences in patterns of change among remote versus on-site workers, as well as the potential beneficial effects of recovery behaviors. These are important contributions given the vital role of essential workers during the pandemic (e.g., healthcare providers, grocery store employees) and the dramatic transition to remote work for non-essential workers, whereas job-stress recovery outside of work is believed to be extremely important for employee well-being (Sonnentag et al., 2017). We also compared the levels of job-related burnout and psychological symptoms we observed in our data with pre-pandemic normative data, thus allowing us to better understand change in employee well-being during the pandemic. Finally, we collected qualitative data to buttress our quantitative recovery findings.

\section{Theoretical Framework}

Two general frameworks that explain stressor-strain relationships include stressreaction and adaptation models. The more popular stress-reaction models (e.g., Bakker \& Demerouti, 2007; Hobfoll, 1989) propose that stressors, such as heightened job demands due to the pandemic, accumulate over time, and prolonged exposure to 
these stressors thus results in both immediate and long-term strain (e.g., increased jobrelated burnout and psychological symptoms across time). The less popular (yet often supported) adaptation models (e.g., Bowling et al., 2005; Diener et al., 2006) suggest that people adapt to stressors over time; thus, the strains produced by an ongoing stressor dissipate over time. That is, adaptation models predict increased levels of momentary strain, but in the longer term, exposure to a stressor results in acclimation and return to set-point levels of well-being (e.g., lower job-related burnout and psychological symptoms across time). As such, these two frameworks offer competing views of the stressor-strain relationship over time. Given the COVID-19 pandemic, the current study provided a unique opportunity to examine these competing theoretical perspectives.

\section{Stress-Reaction Versus Adaptation}

The COVID-19 pandemic is a potential source of many kinds of job stressors, including increased workload, job insecurity, exposure to hazardous work environments, and work-family conflict (for a discussion of various job stressors caused by the pandemic, see Rudolph et al., 2020). We expect, however, that exposure to job stressors will systematically vary from one employee to the next. Exposure to job stressors, for example, may vary based on the severity of the pandemic where one lives. Risk of exposure to the virus may be greatest in "hotspot" areas (e.g., Florida during July 2020), thus adding to the stress of working in those locations. Furthermore, exposure is likely to vary by employment type. The job stressors faced by teleworkers (e.g., having to master the technology necessary to work remotely), for instance, generally differ from the job stressors faced by essential or "on-site" employees (e.g., increased risk of exposure to COVID-19). The current study accounts for both local and occupational differences in pandemic-related job stressors.

It is further important to note that the job stressors created by the pandemic may differ from each other in the permanence of their effects. Consistent with the stressreaction perspective, the pandemic may create job stressors that worsen with time. This may happen if a given job stressor has a cumulative effect on individual employees. A commission salesperson or business owner who has lost customers during the pandemic, for instance, may experience increasing job stress as his or her financial losses continue to mount. Deteriorating effects may be especially likely among job stressors that are less responsive to acclimation processes (for discussions of stressors that are resistant to acclimation, see Lucas, 2005; Lucas et al., 2004). In such instances where workers are unable to acclimate to the stressful conditions posed by the changes in jobs stressors and the emergence of novel stressors, prolonged exposure to stress can result in strain, such as job-related burnout (e.g., physical fatigue, cognitive weariness, and emotional exhaustion at work) and compromised psychological health (Bakker \& Demerouti, 2007, 2014; Schaufeli et al., 2009), which are the outcomes of interest in the current study.

Alternatively, and consistent with the adaptation perspective, an employee's sensitivity to a given job stressor may diminish, even when the stressor persists. A grocery store employee, for example, may initially experience increased job stress associated with possible contact with virus-infected customers. With time, however, the employee is likely to acclimate to that job stressor, even if the actual threat of virus exposure is unchanged. 
Various mechanisms can explain such acclimation effects (see Bowling \& Beehr, 2016; Bowling et al., 2005; Diener et al., 2006). When workers are able to acclimate to job stressors, perceptions of these stressors and the associated strain may decrease over time. Similarly, some job stressors by nature might produce only temporary effects. A given job stressor, for instance, may have a temporary effect when employees quickly learn how to successfully manage that stressor. Employees may be especially adept at quickly learning to manage challenge stressors, as opposed to hindrance stressors (see LePine et al., 2005), as well as stressors that are responsive to problem-focused coping (see Carver et al., 1989). In such cases, an employee may be able to largely or completely eliminate the job stressor. A person forced to work remotely during the pandemic, for instance, may be initially burdened by having to learn to use videoconferencing software. With experience, however, videoconferencing can be quickly mastered.

Given the unprecedented nature of the pandemic, it is difficult to anticipate the strain patterns that workers might display over time; however, tracking workers' strains at various times during the pandemic will yield important insights into how organizations can best respond to this crisis (Sinclair et al., 2020). Drawing from both stress-reaction and adaptation models, we pose the following competing hypotheses (the first is consistent with a stressreaction perspective; the second is consistent with an adaptation perspective):

Hypothesis 1a: As the pandemic progresses, job-related burnout and psychological symptoms will increase over time.

Hypothesis $1 \mathrm{~b}$ : As the pandemic progresses, job-related burnout and psychological symptoms will decrease over time.

\section{Demands of Telework and On-Site Work}

Differences in initial levels and change over time in job-related burnout and mental health could be explained by many contextual and individual factors. The current study examines the impact of job type and recovery behaviors as two such factors. It is important to distinguish between remote work and on-site work, as these settings are likely to produce different pandemic-related stressors. Remote workers, for example, face their own unique set of pandemic-related stressors. The sudden transition to remote work, for instance, has caused many workers to have to care for children at home while working - potentially resulting in increased family-to-work conflict, the need to learn new technology, and the general stressors associated with a sudden shift in the way jobs are performed (Delanoeije et al., 2019; Gajendran \& Harrison, 2007). In contrast, on-site workers who continue to work on the "frontline," such as healthcare workers, grocery workers, and postal workers, are exposed to increased risks of contracting COVID-19 or transmitting the virus to others (Sinclair et al., 2020). The stressors faced by on-site workers may be further compounded by an increased workload.

Given the differing challenges associated with remote work and on-site work, we expect to observe distinct patterns of job-related burnout and psychological symptoms both initially and over time based on employment setting. Though we believe employment type (i.e., telework, on-site work, and working both on-site and remotely) will affect job-related burnout and psychological symptoms, we do not suggest competing hypotheses (cf. Hypothesis 1a and 1b) or specify a direction for the ways in which job type might affect 
outcomes given lack of a priori theory. Accordingly, we provide the following exploratory hypothesis:

Hypothesis 2: Employment type, including telework, on-site work, and working both remotely and on-site, will impact job-related burnout and psychological symptoms over time.

\section{Benefits of Recovery Behaviors}

In addition to type of work, the behaviors that employees engage in to recuperate from pandemic-related job stressors during their leisure time may produce improvements in jobrelated burnout and psychological health over time. Sonnentag and Fritz (2007) describe recovery as a process through which workers' strain is returned to their pre-stressor level. They identified four distinct types of recovery behaviors: psychological detachment, relaxation, mastery experiences, and control during leisure time. Several studies have shown that recovery behaviors are related to improved well-being (see Sonnentag et al., 2017, for a review). A meta-analysis of 54 independent samples by Bennett et al. (2017), for instance, found that recovery behaviors were negatively related to job demands and positively related to both job resources and well-being. Drawing upon previous research, we expect recovery behaviors to contribute to greater well-being by protecting workers against pandemic-related stressors and increasing personal resources.

Hypothesis 3: Recovery behaviors will be associated with improvements in jobrelated burnout and psychological symptoms over time.

\section{Method}

\section{Participants and Procedure}

Given the nature of our hypotheses, it was important to recruit a diverse employed sample dispersed throughout the US; accordingly, we recruited participants using Amazon's Mechanical Turk or MTurk with research ethics committee approval (Auburn University IRB Protocol \#20-048 EX 2001). We used MTurk for several reasons. First, considering the rapid rate of COVID-19 spread across the US, MTurk allowed us to move quickly to collect weekly data across multiple weeks with a large sample. Second, we wanted participants from throughout the US. This is essential given the unpredictable nature of COVID-19 spread, with clusters occurring anytime within counties across the country. Third, MTurk has been shown to be demographically and occupationally diverse, with samples that approximate the US labor force (Behrend et al., 2011; Buhrmester et al., 2011; Michel et al., 2018). Fourth, researchers consistently find that the quality and accuracy of MTurk data are very high, and that organizational and occupational health data collected via MTurk are comparable to published benchmarks (Michel et al., 2018; Schleider \& Weisz, 2015; Sprouse, 2011; Walter et al., 2019). Finally, anonymity associated with MTurk allows to more effectively measure sensitive issues (e.g., one's mental health). 
We collected data from 1000 participants beginning at 12 noon CST Wednesday April 1, 2020 (Time 1). After screening for bots, unemployment outside of MTurk, and excluding anyone who missed one or more instructed-response items (IRIs), ${ }^{1}$ we invited 651 participants for the Time 2 survey at 12 noon CST Wednesday April 8, 2020. The Times 2-5 surveys were opened at 12 noon CST each Wednesday and left open until Friday at 5 pm CST. We collected MTurk IDs during each wave so we could link the data across the five time points. Times 2-4 included four IRIs and participants were retained if they missed no more than one IRIs each week. We chose a cut-off of one IRI because failing one item may indicate transient measurement error due to imperfect scale reliability (McGonagle et al., 2016). The final sample $(N=301)$ consisted of participants who met all of these requirements and maintained at least $10 \mathrm{~h}$ of work outside of MTurk each week throughout the duration of the study (i.e., 12:00 pm CST on Wednesday April 1, 2020, through 5:00 pm CST on Friday May 1, 2020). We paid participants $\$ .50$ for completing the Time 1 survey and $\$ 2.00$ for each for completing the Time $2-5$ surveys. They received an additional $\$ 1.00$ bonus for completing all five questionnaires.

The average participant was 39.3 years of age $(S D=10.9)$ and most participants were male $(66.4 \%)$. Relationship status consisted of $56.5 \%$ married or living with partner/significant other and $46.8 \%$ of the sample had children. Ethnic/racial breakdown consisted of $71.8 \%$ Caucasian/White, $11.3 \%$ Asian/Pacific Islander, $8.3 \%$ African American/Black, 6.6\% Hispanic, .7\% Native American, and 1.3\% other. All participants were employed at least $10 \mathrm{~h}$ or more per week and worked an average of 38.2 h $(S D=8.3)$ each week. Participants held various job titles, including "accountant," "cashier," "data analyst," "general manager," "healthcare provider," "merchant," "plumber," "receptionist," "restaurant manager," and "sales associate."

\section{Measures}

County-Level COVID-19 Cases To control for county-level COVID-19 cases, we collected participant zip codes, which were automatically verifiable by Qualtrics. We recoded zip codes into counties, which we then used to assess county-level cases rates per $100 \mathrm{k}$ as of the Friday of the assessed week. These data were retrieved from USAFacts (https://usafacts.org), which aggregates data from the Centers for Disease Control and Prevention (CDC) — as well as from state- and local-level public health agencies - to provide county-level data that is confirmed by referencing state and local

\footnotetext{
${ }^{1}$ We took several steps to maximize data quality. A prescreen was listed on MTurk for a study on "life roles, employment/unemployment, and health during the COVID-19 pandemic." Per previous recommendations, we set MTurk "worker" qualification requirements to an approval rating of $>95$ and a number of approved tasks to $\geq 100$ (Peer et al., 2014). We also limited our MTurk participants to US workers. To block "suspicious MTurk activity," we used CloudResearch, which has an extensive database on MTurk workers (Litman et al., 2017). The prescreen (i.e., Time 1) Qualtrics survey included a reCAPTCHA and the question "This page is designed to identify bots prior to our survey. Please select the emergency phone number within the United States" with answers of 411, 611, and 911, to screen for bots (Yarrish et al., 2019). We also included three instructedresponse items (e.g., "Please select strongly agree for this item") mixed into the demographic questionnaire and baseline survey to capture careless responding (see Gummer et al., 2018; Huang et al., 2015; Meade \& Craig, 2012).
} 
agencies directly. ${ }^{2}$ Data used in the current study corresponds to Time $1=$ Friday April 3, 2020 through Time $5=$ Friday May 1, 2020.

Jobsite Location To assess jobsite location, we asked several questions beyond our general screening items (e.g., currently employed outside of MTurk, hours worked over the last week outside of MTurk). Specifically, we asked two items related to telework use and frequency and two items related to on-site work and frequency at Times 1-5. The first set of items were "Are you currently teleworking/working from home/e-commuting for some of your work hours?" $(1=$ yes, $2=n o)$ followed by an open ended item "Approximately how many hours did you telework/work from home/e-commute over the last week?". The second set of items were "Are you currently working at your regular job site for some of your work hours?" ( $1=y e s, 2=$ no, 3 = not applicable $)$ followed by an open ended item "Approximately how many hours did you work on your regular non-home job site over the last week?". From these responses we created dummy variables consisting of "telework," "on-site work," and "jobsite varies," where each variable was dummy code as $1=y e s$ and $0=$ no. The final sample included 174 teleworkers, 68 on-site workers, and 59 employees that engaged in both remote and on-site work.

Recovery Behaviors We assessed job-related recovery at Times 2-4 with the 16-item Recovery Experience Questionnaire (Sonnentag \& Fritz, 2007). This measure assesses how people recuperate from work during leisure time and includes behaviors related to psychological detachment, relaxation, mastery experiences, and control during leisure time. Instructions at Time 2 were "Since the pandemic, during my leisure time" and instructions at Times 3-5 were "Over the last week, during my leisure time." Sample items include "I don't think about work at all," "I kick back and relax," "I do things that challenge me," and "I decide my own schedule." Responses ranged from 1 (strongly disagree) to 5 (strongly agree).

Job-Related Burnout We assessed job-related burnout at Times 1-5 with the 14-item Shirom-Melamed Burnout Measure (SMBM; Shirom \& Melamed, 2006). This measure assesses physical fatigue, cognitive weariness, and emotional exhaustion at work and exhibits strong psychometrics (e.g., internal consistency, factor structure, measurement invariance, convergent and discriminant validity) across a variety of populations (e.g., Gerber et al., 2018; Lundgren-Nilsson et al., 2012; Schilling et al., 2019; Shirom $\&$ Melamed, 2006). The Time 1 instructions were "Please indicate how often, since the start of the pandemic, you have felt each of the following feelings" and the Time 2-5 instructions were "Please indicate how often, over the last week, you have felt each of the following feelings." Example items include "I feel physically drained" (physical fatigue), "I have difficulty concentrating" (cognitive weariness), and "I feel I am unable to be sensitive to the needs of coworkers and customers" (emotional exhaustion). Responses ranged from 1 (never or almost never) to 7 (always or almost always).

Psychological Symptoms Psychological health symptoms were assessed at Times 1-5 with the 12-item General Health Questionnaire (GHQ-12; Goldberg, 1978). The Time

\footnotetext{
${ }^{2}$ Considering Alaska and Louisiana do not have counties, we used borough or census area data for Alaska and parish data for Louisiana.
} 
1 instructions were, "Since the start of the pandemic, have you," and the Time 2-5 instructions were, "Over the last week, have you." Example items include "lost much sleep over worry" and "felt you couldn't overcome your difficulties." Responses ranged from 1 (not at all) to 4 (much more than usual).

Pre-Pandemic Norms In order to compare our criterion measure scores to pre-pandemic norms, we conducted Google Scholar literature searches on the terms Shirom-Melamed Burnout Measure and GHQ-12 paired with MTurk. Samples were included in our normative data if the study used the same items and response scales as the current study. This resulted in six studies for the SMBM (Barber \& Santuzzi, 2015; Chopik, 2015; Chung, 2016; Santuzzi \& Barber, 2018; Varghese et al., 2020; Wilkes et al., 2018) and three studies for the GHQ-12 (Early, 2013; Hudson \& Shen, 2018; Tarabay, 2015).

Qualitative Data To supplement our quantitative recovery data, we asked the following open-ended question: "Are there any strategies you use to cope with work stressors during the COVID-19 pandemic that were not listed here?" Of the 301 respondents in the final sample, 224 answered the qualitative item resulting in a completion rate of $74.4 \%$ with an average response length of 9.7 words. Responses were analyzed in NVivo 12 Plus software and themes were interpreted through discussion of results by all authors until absolute agreement was achieved.

\section{Results}

Table 1 reports the descriptive statistics, reliabilities, and correlations for our study variables. For the telework, on-site work, and jobsite varies variables, each participant had one dummy code of 1 and two dummy codes of 0 . For example, a participant classified as a teleworker was coded as a $1=$ yes for the telework variable and a $0=n o$ for the on-site and jobsite varies variables. Thus, bivariate correlations are interpreted independently (i.e., absence of a reference group). Results indicate telework was negatively related to one of the five emotional exhaustion time points, on-site work was negatively related to two of the five cognitive weariness time points, and varied jobsite was positively related to two of the five cognitive weariness time points and four of the five emotional exhaustion time points. As expected, recovery behaviors were consistently and negatively related to all outcome variables (i.e., the burnout dimensions and psychological symptoms), whereas all outcome variables were positively related to each other. Perhaps surprisingly, however, county-level COVID cases were unrelated to outcomes variables.

\section{Latent Growth Model Testing}

Measurement Invariance Prior to hypothesis testing, we examined measurement invariance for each outcome variable across all five time points. Considering that we examined single factors for our outcomes, including physical fatigue, cognitive weariness, emotional exhaustion, and psychological symptoms, we used a longitudinal common factor model where all four variables were examined simultaneously (see 


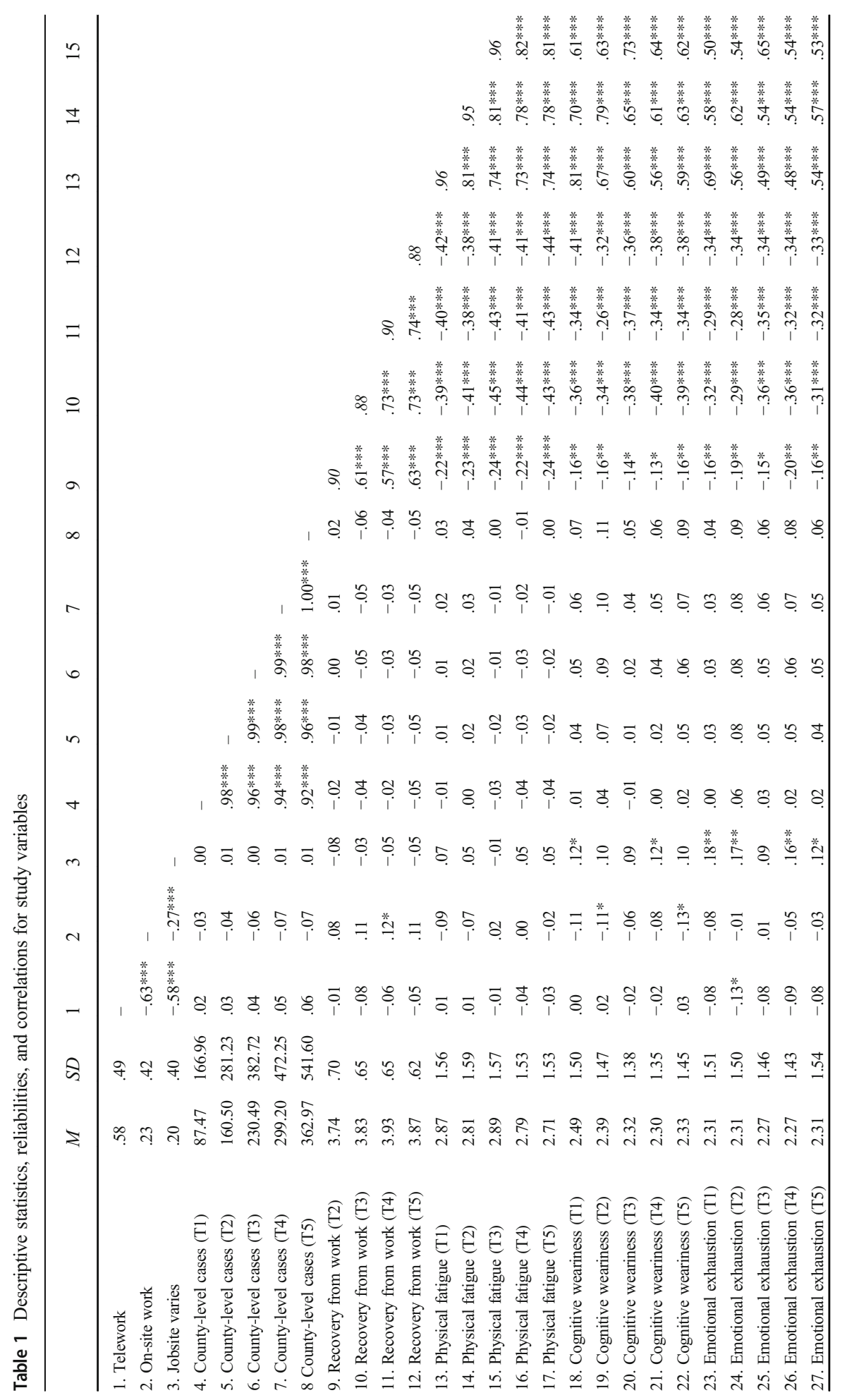




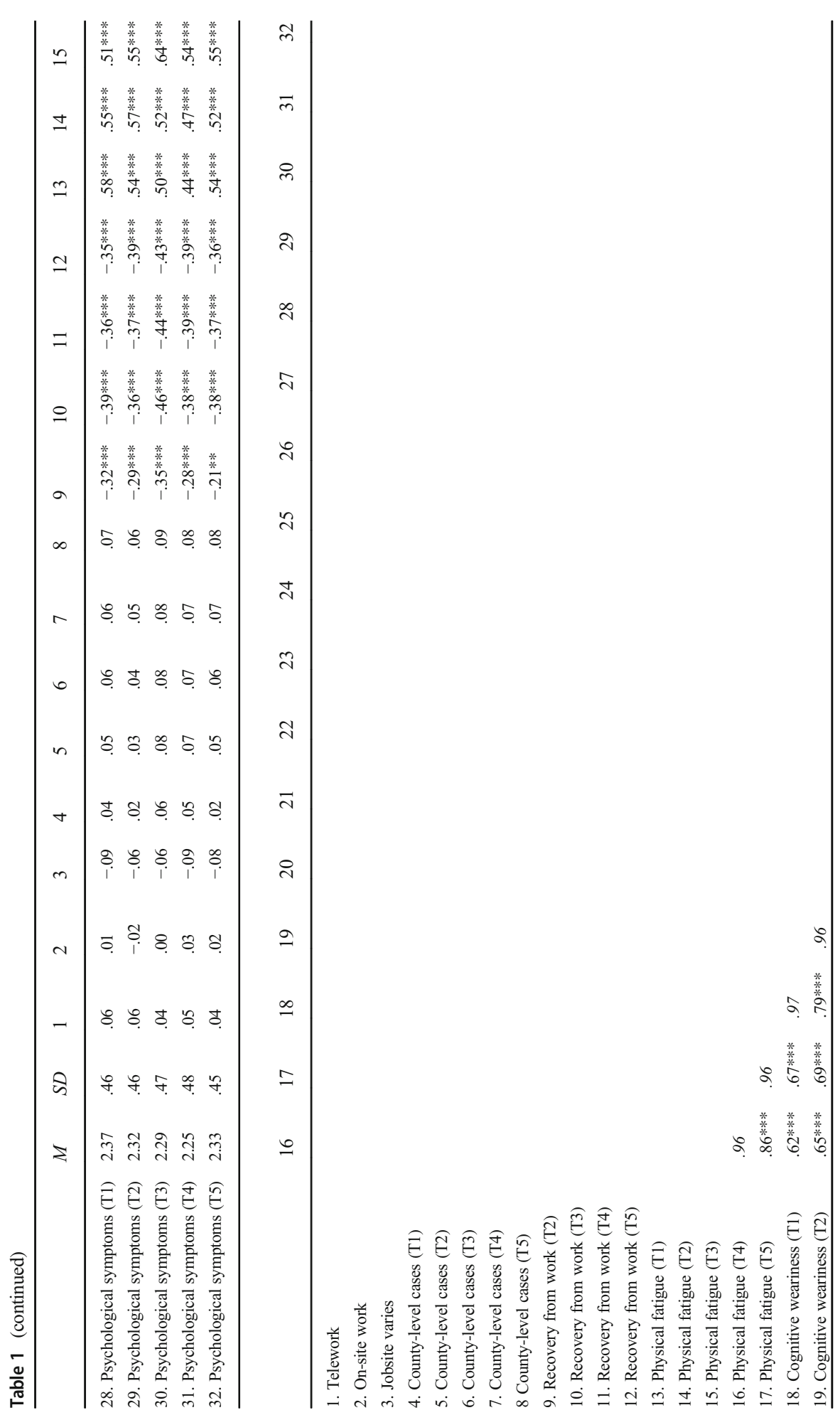




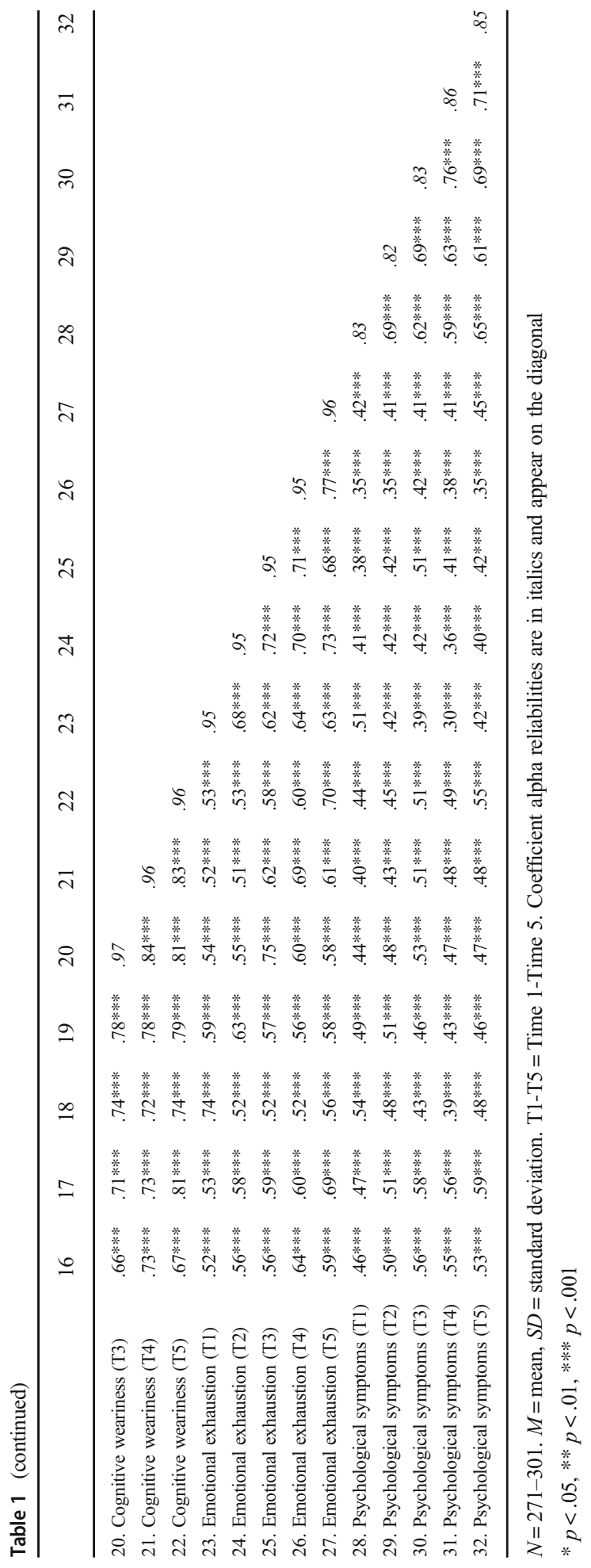


Table 2 Measurement Invariance for Full Measurement Model of Study Outcomes

\begin{tabular}{|c|c|c|c|c|c|c|c|c|}
\hline & \multirow[t]{2}{*}{$X^{2}$} & \multirow[t]{2}{*}{$d f$} & \multirow[t]{2}{*}{ CFI } & \multirow[t]{2}{*}{ TLI } & \multirow[t]{2}{*}{ SRMR } & \multirow[t]{2}{*}{ RMSEA } & \multicolumn{2}{|c|}{$90 \% \mathrm{CI}$} \\
\hline & & & & & & & Lower & Upper \\
\hline Configural Invariance Model & 201.19 & 120 & .99 & .98 & .07 & .05 & .036 & .059 \\
\hline Metric Invariance Model & 216.59 & 132 & .99 & .98 & .07 & .05 & .035 & .057 \\
\hline
\end{tabular}

$N=271 . \chi^{2}$, chi-square; $d f$, degrees of freedom; $C F I$, comparative fit index; TLI, Tucker-Lewis index; SRMR, standardized root mean square residual; RMSEA, root mean square error of approximation; $C I$, confidence interval of RMSEA

Grimm et al., 2017). A longitudinal common factor model specifies each time point as a common factor of each indicator, and thus allows for tests of measurement invariance across time (Kim \& Willson, 2014). Additionally, we used Vandenberg and Morelli's (2016) recommendations to test for configural and metric invariance. A configural invariance model "constrains the number of factors and pattern of zero and nonzero loadings to be identical across measurement occasions" (Grimm et al., 2017, p. 347), whereas a metric invariance model "creates proportional covariance structures across time" (Grimm et al., 2017, p. 348) to indicate whether "each item contributes to the latent construct to a similar degree across groups" or, in this case, time points (Putnick $\&$ Bornstein, 2016, p. 175). The results of these analyses, which are reported in Table 2, indicated very good fit for both the configural and metric invariance measurement models.

Hypotheses 1a and $1 \mathrm{~b}$ Our competing hypotheses proposed that as the pandemic progressed, either job-related burnout and psychological symptoms would increase over time (Hypothesis 1a; i.e., the stress-reaction model), or that job-related burnout and psychological symptoms would decrease over time (Hypothesis 1b; i.e., the adaptation model). We tested these hypotheses using latent growth modeling (LGM), which allowed us to examine the effects of time on the outcome variables (Baethge et al., 2020; Duncan et al., 2013; Preacher et al., 2008). Systemic within-person change across the five time points was examined by specifying latent intercept, linear slope, and quadratic growth factors for each of the dependent variables, and then estimating the means and variances of these latent terms. Linear growth terms remain consistent from time period to time period, whereas quadratic growth terms represent acceleration/ deceleration, or the extent to which the rate of change itself changes over time. Linear factors for Times $1-5$ were specified to be $0-4$, whereas factors for the latent quadratic growth term were specified for Times 2-5 to be 1, 4, 9, and 16. These analyses were performed using Mplus (Muthén \& Muthen, 2017). We investigated our hypotheses controlling for the number of cases reported in respondents' home counties at each week of data collection, as suggested by Rudolph et al. (2020). County cases per 100,000 residents were included as a time-varying covariate (i.e., time-specific observed variables were directly regressed on county case data at respective time points).

As reported in Table 3, these models exhibited very good fit. Respondents exhibited downward change across time in cognitive weariness $(-.12, p=.026)$ and psychological symptoms $(-.09, p<.001)$ as indicated by significant negative linear slope means. 


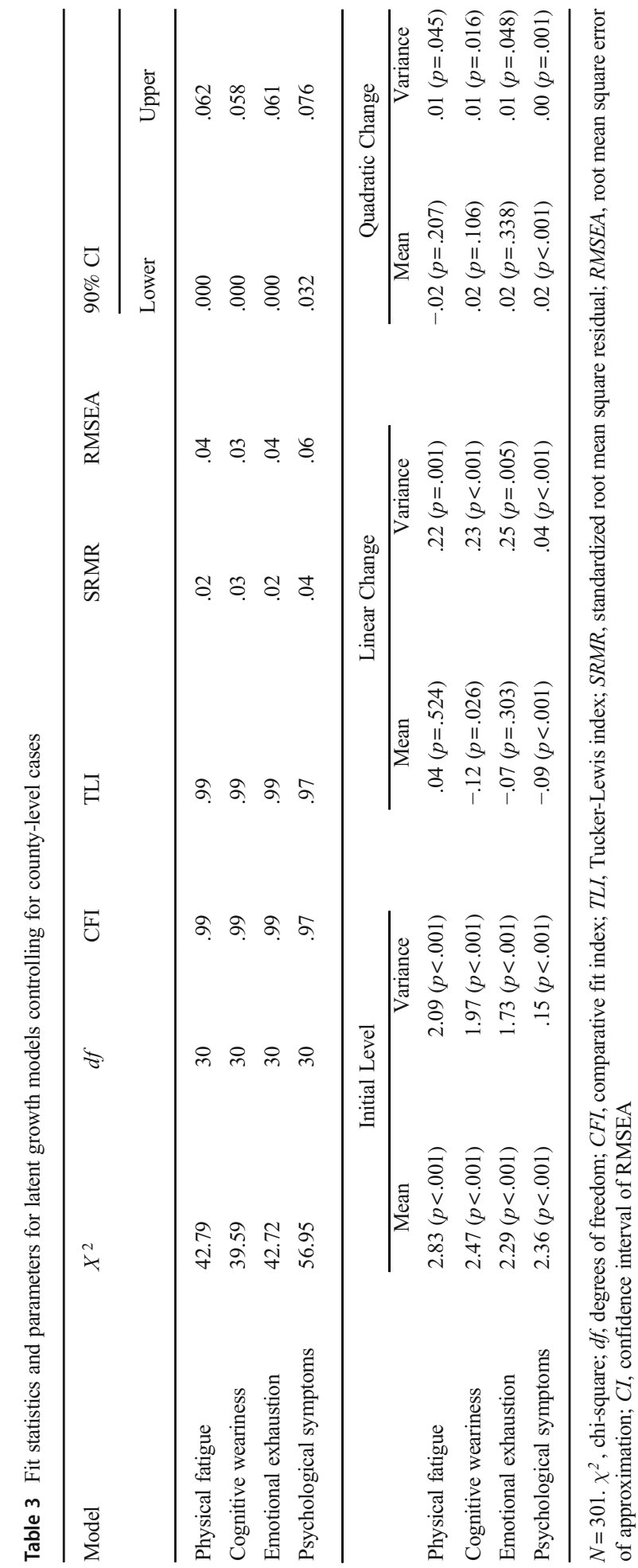


2.5

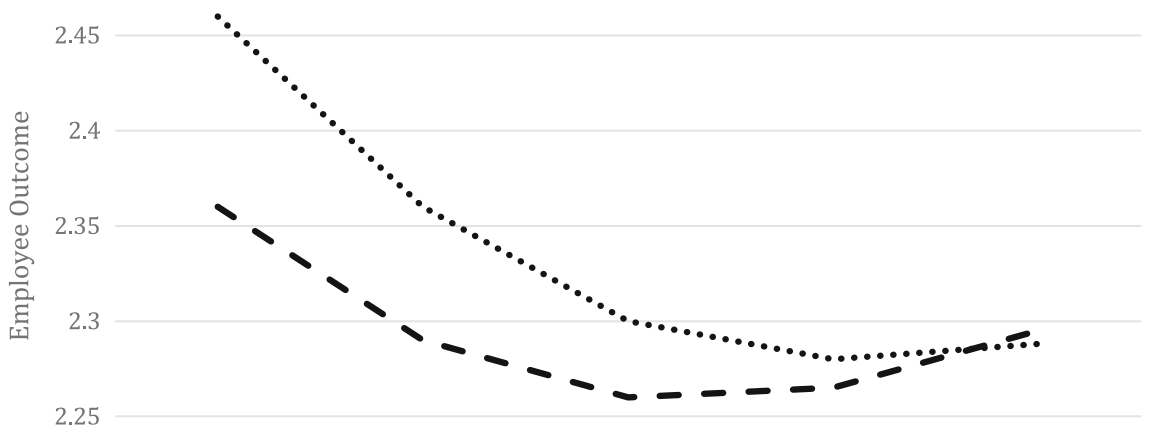

2.2

2

3

4

5

Time Points

Cognitive Weariness

Psychological Symptoms

Fig. 1 Change in cognitive weariness and psychological symptoms over time. Note: Time points indicate weekly surveys beginning April 1, 2020, and concluding April 29, 2020

Furthermore, the change in respondents' psychological symptoms decelerated over time as indicated by a significant and positive quadratic growth mean $(.02, p<.001)$. Mean changes in cognitive weariness and psychological symptoms are displayed in Fig. 1. In sum, our analyses for cognitive weariness and psychological health support Hypothesis 1b, whereas we observed no support for Hypothesis 1a. Furthermore, it is noteworthy that the remaining two dimensions of burnout, physical fatigue and emotional exhaustion, displayed no change. Thus, the Hypothesis 1 analyses suggests that our participants generally displayed high levels of resilience in response to the pandemic, providing more support for the adaptation model versus stress-reaction model.

Hypothesis 2 Our second hypothesis suggested employment type, including telework, on-site work, and working both remotely and on-site, would impact job-related burnout and psychological symptoms over time. We tested Hypothesis 2 by specifying respondents' working location as a time-invariant variable controlling for county-level cases. Working locations were dummy-coded as described in the Method section, with the dummy codes for telework and on-site work entered into the regression, such that the third group that engaged in both remote and on-site work acts as a reference group. We regressed the latent intercept, linear slope, and quadratic growth terms on respondents' working locations (controlling for county-level cases), and tested our hypothesis by examining these regression coefficients.

As reported in Table 4, these models showed very good fit. Latent intercepts indicated that on-site workers exhibited a lower level of cognitive weariness at Time 1 when compared to those who worked remotely and on-site, as evidenced by the significant negative coefficient on the intercept term $(-.69, p=.009)$, whereas both teleworkers $(-.66, p=.003)$ and on-site workers $(-.74, p=.005)$ reported lower emotional exhaustion at Time 1 , as compared to those who had varied jobsites. These 


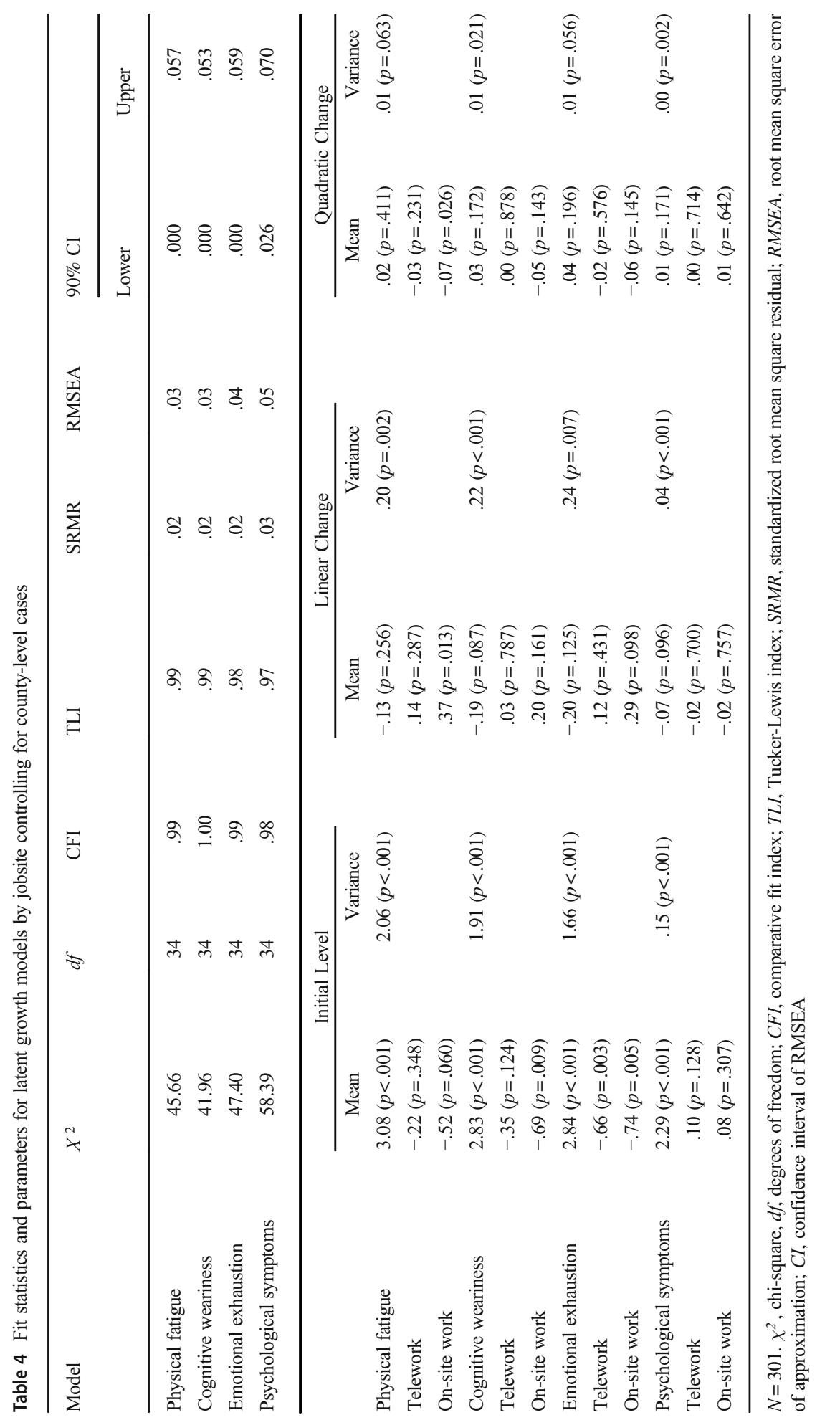




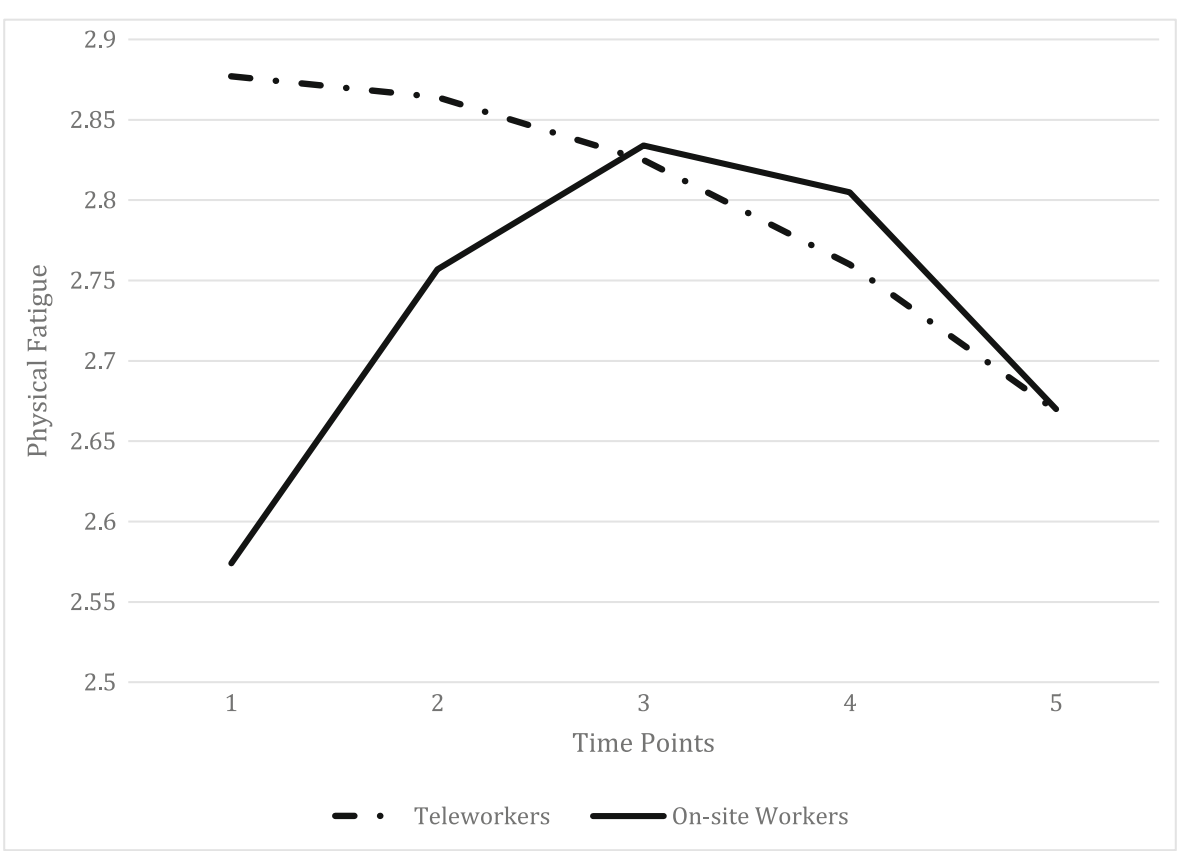

Fig. 2 Change in physical fatigue over time for teleworkers and on-site workers. Note: Time points indicate weekly surveys beginning April 1, 2020, and concluding April 29, 2020

results suggest that working solely on-site or remotely, versus engaged in both telework and on-site work, may have had beneficial effects on cognitive weariness and emotional exhaustion at our initial assessment. However, the linear slope and quadratic growth factors indicated that on-site workers exhibited an increase in physical fatigue over time, evidenced by the significant positive coefficient on the linear change term $(.37, p=.013)$, and this fatigue decelerated over time as indicated by the significant negative coefficient on the quadratic growth term $(-.07, p=.026)$. Mean changes in physical fatigue are displayed separately in Fig. 2 for teleworkers and on-site workers. Collectively, these results provide support for Hypothesis 2, such that we found higher initial levels of cognitive weariness and emotional exhaustion for workers that engaged in both remote and on-site work, and an increase in physical fatigue over time for onsite workers, though this increase decelerated over time. We did not find job type differences for psychological symptoms initially or across time.

We also examined mean differences by jobsite for outcome variables across the five time points with one-way ANOVAs and subsequent Tukey HSD Multiple Comparisons Post-Hoc Tests. We did not find mean differences in physical fatigue by jobsite across any of the time points (see Table 5). Similar to our LGM latent intercept results, we found that onsite workers and varied jobsite workers experienced different levels of cognitive weariness, with on-site workers reporting lower overall levels at Time 1 (mean difference $=-.67$, $S E=.27, p=.032$ ) and Time 5 (mean difference $=-.64, S E=.26, p=.034$ ). These results are reported in Table 6. Likewise, we found that both teleworkers (mean difference $=-.64$, $S E=.23, p=.014$ ) and on-site workers (mean difference $=-.75, S E=.27, p=.013$ ) reported lower emotional exhaustion at Time 1 than workers from varied jobsites. Additionally, we found teleworkers also reported lower emotional exhaustion at Time 2 (mean difference $=$ 
Table 5 Mean differences in physical fatigue at each time by jobsite

\begin{tabular}{|c|c|c|c|c|c|c|c|c|c|c|c|}
\hline & \multirow[t]{2}{*}{$n$} & \multirow[t]{2}{*}{ Mean } & \multicolumn{3}{|c|}{$\begin{array}{l}\text { Mean Difference } \\
{[\text { mean }-(a)]}\end{array}$} & \multicolumn{3}{|c|}{$\begin{array}{l}\text { Mean Difference } \\
{[\text { mean }-(b)]}\end{array}$} & \multicolumn{3}{|c|}{$\begin{array}{l}\text { Mean Difference } \\
{[\text { mean - (c) }]}\end{array}$} \\
\hline & & & Difference & se & $p$ & Difference & se & $p$ & Difference & se & $p$ \\
\hline Physical Fatigue (T1) & 301 & 2.87 & & & & & & & & & \\
\hline Telework (a) & 174 & 2.89 & - & - & - & .26 & .22 & .462 & -.22 & .23 & .628 \\
\hline On-site work (b) & 68 & 2.63 & -.26 & .22 & .462 & - & - & - & -.48 & .28 & .195 \\
\hline Jobsite varies (c) & 59 & 3.10 & .22 & .23 & .628 & .48 & .28 & .195 & - & - & - \\
\hline Physical Fatigue (T2) & 301 & 2.81 & & & & & & & & & \\
\hline Telework (a) & 174 & 2.82 & - & - & - & .21 & .23 & .632 & -.16 & .24 & .795 \\
\hline On-site work (b) & 68 & 2.62 & -.21 & .23 & .632 & - & - & - & -.36 & .28 & .407 \\
\hline Jobsite varies (c) & 59 & 2.98 & .16 & .24 & .795 & .36 & .28 & .407 & - & - & - \\
\hline Physical Fatigue (T3) & 301 & 2.89 & & & & & & & & & \\
\hline Telework (a) & 174 & 2.87 & - & - & - & -.08 & .23 & .935 & .00 & .24 & 1.00 \\
\hline On-site work (b) & 68 & 2.95 & .08 & .23 & .935 & - & - & - & .08 & .28 & .958 \\
\hline Jobsite varies (c) & 59 & 2.87 & .00 & .24 & 1.00 & -.08 & .28 & .958 & - & - & - \\
\hline Physical Fatigue (T4) & 301 & 2.79 & & & & & & & & & \\
\hline Telework (a) & 174 & 2.73 & - & - & - & -.06 & .22 & .966 & -.20 & .23 & .668 \\
\hline On-site work (b) & 68 & 2.79 & .06 & .22 & .966 & - & - & - & -.14 & .27 & .859 \\
\hline Jobsite varies (c) & 59 & 2.93 & .20 & .23 & .668 & .14 & .27 & .859 & - & - & - \\
\hline Physical Fatigue (T5) & 301 & 2.71 & & & & & & & & & \\
\hline Telework (a) & 174 & 2.66 & - & - & - & .02 & .22 & .997 & -.20 & .23 & .667 \\
\hline On-site work (b) & 68 & 2.87 & -.02 & .22 & .997 & - & - & - & -.21 & .27 & .713 \\
\hline Jobsite varies (c) & 59 & 2.71 & .20 & .23 & .667 & .21 & .27 & .713 & - & - & - \\
\hline
\end{tabular}

Difference statistics from one-way ANOVAs and Tukey HSD multiple comparisons post-hoc tests. T1-T5 = Time 1-Time 5

-.67, $S E=.22, p=.009$ ) and Time 4 (mean difference $=-.57, S E=.21, p=.023$ ) than workers from varied jobsites. These results are reported in Table 7. Similar to our LGM results, we did not find any mean differences in psychological symptoms by jobsite across any of the time points (see Table 8).

Hypothesis 3 Our final hypothesis proposed that recovery behaviors would be associated with improvements in job-related burnout and psychological symptoms over time. We tested Hypothesis 3 by added recovery behaviors reported at Times $2-5$ as a timevarying covariate, with time-specific observed variables directly regressed on respondent recovery data at each respective time point, controlling for county-level cases. To interpret the impact of recovery on well-being outcomes, these results can be compared to those without recovery as a time-varying covariate.

As reported in Table 9, models with recovery as a time-varying covariate indicated good fit. When compared to the results reported in Table 3 (i.e., recovery not included as a time-varying covariate), there were no longer significant systemic trends in withinperson cognitive weariness or psychological symptoms when adding respondents' recovery behaviors as a covariate. Thus, the inclusion of overall recovery behaviors 
Table 6 Mean differences in cognitive weariness at each time by jobsite

\begin{tabular}{|c|c|c|c|c|c|c|c|c|c|c|c|}
\hline & \multirow[t]{2}{*}{$n$} & \multirow[t]{2}{*}{ Mean } & \multicolumn{3}{|c|}{$\begin{array}{l}\text { Mean difference } \\
{[\text { mean - (a) }]}\end{array}$} & \multicolumn{3}{|c|}{$\begin{array}{l}\text { Mean difference } \\
{[\text { mean }-(b)]}\end{array}$} & \multicolumn{3}{|c|}{$\begin{array}{l}\text { Mean difference } \\
{[\text { mean }-(\mathrm{c})]}\end{array}$} \\
\hline & & & Difference & se & $p$ & Difference & se & $p$ & Difference & se & $p$ \\
\hline $\begin{array}{l}\text { Cognitive Weariness } \\
\text { (T1) }\end{array}$ & 301 & 2.49 & & & & & & & & & \\
\hline Telework (a) & 174 & 2.49 & - & - & - & .31 & .21 & .324 & -.37 & .23 & .236 \\
\hline On-site work (b) & 68 & 2.18 & -.31 & .21 & .324 & - & - & - & -.67 & .27 & .032 \\
\hline Jobsite varies (c) & 59 & 2.86 & .37 & .23 & .236 & .67 & .27 & .032 & - & - & - \\
\hline $\begin{array}{l}\text { Cognitive Weariness } \\
\text { (T2) }\end{array}$ & 301 & 2.39 & & & & & & & & & \\
\hline Telework (a) & 174 & 2.41 & - & - & - & .33 & .21 & .259 & -.28 & .22 & .407 \\
\hline On-site work (b) & 68 & 2.08 & -.33 & .21 & .259 & - & - & - & -.61 & .26 & .051 \\
\hline Jobsite varies (c) & 59 & 2.69 & .28 & .22 & .407 & .61 & .26 & .051 & - & - & - \\
\hline $\begin{array}{l}\text { Cognitive Weariness } \\
\text { (T3) }\end{array}$ & 301 & 2.32 & & & & & & & & & \\
\hline Telework (a) & 174 & 2.29 & - & - & - & .14 & .20 & .759 & -.28 & .21 & .365 \\
\hline On-site work (b) & 68 & 2.15 & -.14 & .20 & .759 & - & - & - & -.42 & .24 & .200 \\
\hline Jobsite varies (c) & 59 & 2.57 & .28 & .21 & .365 & .42 & .24 & .200 & - & - & - \\
\hline $\begin{array}{l}\text { Cognitive Weariness } \\
\text { (T4) }\end{array}$ & 301 & 2.30 & & & & & & & & & \\
\hline Telework (a) & 174 & 2.27 & - & - & - & .18 & .19 & .631 & -.34 & .20 & .215 \\
\hline On-site work (b) & 68 & 2.09 & -.18 & .19 & .631 & - & - & - & -.52 & .24 & .080 \\
\hline Jobsite varies (c) & 59 & 2.61 & .34 & .20 & .215 & .52 & .24 & .080 & - & - & - \\
\hline $\begin{array}{l}\text { Cognitive Weariness } \\
\text { (T5) }\end{array}$ & 301 & 2.33 & & & & & & & & & \\
\hline Telework (a) & 174 & 2.37 & - & - & - & .39 & .21 & .146 & -.25 & .22 & .472 \\
\hline On-site work (b) & 68 & 1.98 & -.39 & .21 & .146 & - & - & - & -.64 & .26 & .034 \\
\hline Jobsite varies (c) & 59 & 2.62 & .25 & .22 & .472 & .64 & .26 & .034 & - & - & - \\
\hline
\end{tabular}

Difference statistics from one-way ANOVAs and Tukey HSD multiple comparisons post-hoc tests. T1-T5 = Time 1-Time 5

resulted in models that indicated no evidence of systemic change in any of the variables, whereas prior models without recovery behaviors indicated downward change in cognitive weariness and psychological symptoms, as well as deceleration in psychological symptoms. In other words, engaging in recovery behaviors outside of work, over time, accounted for systematic linear change in cognitive weariness and psychological symptoms, and quadratic growth in psychological symptoms, over time. ${ }^{3}$

\footnotetext{
${ }^{3}$ Supplementing the analyses that tested Hypothesis 2, we examined respondent recovery behaviors reported at Times $2-5$ as a time-varying covariate to the jobsite models controlling for county-level cases. Though these models fit the data well, the linear change and quadratic growth coefficients for on-site workers remained significant. These results suggest that engaging in general recovery behaviors outside of work do not account for systematic linear change or decreased rate of change over time for on-site workers.
} 
Table 7 Mean differences in emotional exhaustion at each time by jobsite

\begin{tabular}{|c|c|c|c|c|c|c|c|c|c|c|c|}
\hline & \multirow[t]{2}{*}{$n$} & \multirow[t]{2}{*}{ Mean } & \multicolumn{3}{|c|}{$\begin{array}{l}\text { Mean Difference } \\
{[\text { mean }-(a)]}\end{array}$} & \multicolumn{3}{|c|}{$\begin{array}{l}\text { Mean Difference } \\
{[\text { mean }-(b)]}\end{array}$} & \multicolumn{3}{|c|}{$\begin{array}{l}\text { Mean Difference } \\
{[\text { mean }-(\mathrm{c})]}\end{array}$} \\
\hline & & & Difference & se & $p$ & Difference & se & $p$ & Difference & se & $p$ \\
\hline $\begin{array}{l}\text { Emotional Exhaustion } \\
\text { (T1) }\end{array}$ & 301 & 2.31 & & & & & & & & & \\
\hline Telework (a) & 174 & 2.21 & - & - & - & .12 & .21 & .842 & -.64 & .23 & .014 \\
\hline On-site work (b) & 68 & 2.09 & -.12 & .21 & .842 & - & - & - & -.75 & .27 & .013 \\
\hline Jobsite varies (c) & 59 & 2.85 & .64 & .23 & .014 & .75 & .27 & .013 & - & - & - \\
\hline $\begin{array}{l}\text { Emotional Exhaustion } \\
\text { (T2) }\end{array}$ & 301 & 2.31 & & & & & & & & & \\
\hline Telework (a) & 174 & 2.15 & - & - & - & -.14 & .21 & .793 & -.67 & .22 & .009 \\
\hline On-site work (b) & 68 & 2.29 & .14 & .21 & .793 & - & - & - & -.53 & .26 & .113 \\
\hline Jobsite varies (c) & 59 & 2.82 & .67 & .22 & .009 & .53 & .26 & .113 & - & - & - \\
\hline $\begin{array}{l}\text { Emotional Exhaustion } \\
\text { (T3) }\end{array}$ & 301 & 2.27 & & & & & & & & & \\
\hline Telework (a) & 174 & 2.17 & - & - & - & -.11 & .21 & .860 & -.36 & .22 & .228 \\
\hline On-site work (b) & 68 & 2.28 & .11 & .21 & .860 & - & - & - & -.25 & .26 & .595 \\
\hline Jobsite varies (c) & 59 & 2.53 & .36 & .22 & .228 & .25 & .26 & .595 & - & - & - \\
\hline $\begin{array}{l}\text { Emotional Exhaustion } \\
\text { (T4) }\end{array}$ & 301 & 2.27 & & & & & & & & & \\
\hline Telework (a) & 174 & 2.17 & - & - & - & .02 & .20 & .995 & -.57 & .21 & .023 \\
\hline On-site work (b) & 68 & 2.15 & -.02 & .20 & .995 & - & - & - & -.59 & .25 & .054 \\
\hline Jobsite varies (c) & 59 & 2.73 & .57 & .21 & .023 & .59 & .25 & .054 & - & - & - \\
\hline $\begin{array}{l}\text { Emotional Exhaustion } \\
\text { (T5) }\end{array}$ & 301 & 2.31 & & & & & & & & & \\
\hline Telework (a) & 174 & 2.21 & - & - & - & -.02 & .22 & .996 & -.48 & .23 & .097 \\
\hline On-site work (b) & 68 & 2.23 & .02 & .22 & .996 & - & - & - & -.46 & .27 & .212 \\
\hline Jobsite varies (c) & 59 & 2.69 & .48 & .23 & .097 & .46 & .27 & .212 & - & - & - \\
\hline
\end{tabular}

Difference statistics from one-way ANOVAs and Tukey HSD multiple comparisons post-hoc tests. T1-T5 = Time 1-Time 5

We then conducted post-hoc analyses for individual recovery behaviors (i.e., examination of individual psychological detachment, relaxation, mastery experiences, and control during leisure time factors versus an overall recovery construct). Results indicated that the linear change in cognitive weariness, as well as the linear and quadratic changes in psychological symptoms, were accounted for by psychological detachment, relaxation, mastery experiences, and control during leisure time when these recovery behaviors were examined as individual covariates controlling for county-level cases. In sum, our results provide support for the beneficial effects of recovery behaviors, both as an overall construct and as individual factors, in association with job-related burnout and psychological symptoms as outlined in Hypothesis 3. 
Table 8 Mean differences in psychological symptoms at each time by jobsite

\begin{tabular}{|c|c|c|c|c|c|c|c|c|c|c|c|}
\hline & \multirow[t]{2}{*}{$n$} & \multirow[t]{2}{*}{ Mean } & \multicolumn{3}{|c|}{$\begin{array}{l}\text { Mean difference } \\
{[\text { mean }-(a)]}\end{array}$} & \multicolumn{3}{|c|}{$\begin{array}{l}\text { Mean difference } \\
{[\text { mean }-(b)]}\end{array}$} & \multicolumn{3}{|c|}{$\begin{array}{l}\text { Mean difference } \\
{[\text { mean }-(\mathrm{c})]}\end{array}$} \\
\hline & & & Difference & se & $p$ & Difference & se & $p$ & Difference & se & $p$ \\
\hline $\begin{array}{l}\text { Psychological } \\
\text { Symptoms (T1) }\end{array}$ & 301 & 2.37 & & & & & & & & & \\
\hline Telework (a) & 174 & 2.40 & - & - & - & .02 & .07 & .968 & .11 & .07 & .252 \\
\hline On-site work (b) & 68 & 2.38 & -.02 & .07 & .968 & - & - & - & .09 & .08 & .484 \\
\hline Jobsite varies (c) & 59 & 2.29 & -.11 & .07 & .252 & -.09 & .08 & .484 & - & - & - \\
\hline $\begin{array}{l}\text { Psychological } \\
\text { Symptoms (T2) }\end{array}$ & 301 & 2.32 & & & & & & & & & \\
\hline Telework (a) & 174 & 2.34 & - & - & - & .04 & .07 & .841 & .08 & .07 & .471 \\
\hline On-site work (b) & 68 & 2.30 & -.04 & .07 & .841 & - & - & - & .04 & .08 & .851 \\
\hline Jobsite varies (c) & 59 & 2.26 & -.08 & .07 & .471 & -.04 & .08 & .851 & - & - & - \\
\hline $\begin{array}{l}\text { Psychological } \\
\text { Symptoms (T3) }\end{array}$ & 301 & 2.29 & & & & & & & & & \\
\hline Telework (a) & 174 & 2.31 & - & - & - & .01 & .07 & .977 & .07 & .07 & .560 \\
\hline On-site work (b) & 68 & 2.29 & -.01 & .07 & .977 & - & - & - & .06 & .08 & .762 \\
\hline Jobsite varies (c) & 59 & 2.24 & -.07 & .07 & .560 & -.06 & .08 & .762 & - & - & - \\
\hline $\begin{array}{l}\text { Psychological } \\
\text { Symptoms (T4) }\end{array}$ & 301 & 2.25 & & & & & & & & & \\
\hline Telework (a) & 174 & 2.27 & - & - & - & -.01 & .07 & .992 & .11 & .07 & .310 \\
\hline On-site work (b) & 68 & 2.28 & .01 & .07 & .992 & - & - & - & .11 & .09 & .377 \\
\hline Jobsite varies (c) & 59 & 2.17 & -.11 & .07 & .310 & -.11 & .09 & .377 & - & - & - \\
\hline $\begin{array}{l}\text { Psychological } \\
\text { Symptoms (T5) }\end{array}$ & 301 & 2.33 & & & & & & & & & \\
\hline Telework (a) & 174 & 2.34 & - & - & - & .00 & .06 & .999 & .09 & .07 & .412 \\
\hline On-site work (b) & 68 & 2.35 & .00 & .06 & .999 & - & - & - & .09 & .08 & .510 \\
\hline Jobsite varies (c) & 59 & 2.26 & -.09 & .07 & .412 & -.09 & .08 & .510 & - & - & - \\
\hline
\end{tabular}

Difference statistics from one-way ANOVAs and Tukey HSD multiple comparisons post-hoc tests. T1-T5 = Time 1-Time 5

\section{Supplemental Analyses}

Pre-Pandemic Outcome Norms To test for significant difference between pre-pandemic and current study outcomes, we calculated sample-size-weighted means $(M)$ and standard deviations $(S D)$ for the pre-pandemic criteria (physical fatigue, $M=3.47, S D$ 1.48; cognitive weariness, $M=2.84, S D=1.32$; emotional exhaustion, $M=2.64, S D=$ 1.46; and psychological symptoms, $M=1.89, S D .44$ ). Compared to the Time $1 M$ and $S D$ presented in Table 1, independent sample $t$-tests (assuming equal variances) indicated that physical fatigue $(t[1762]=6.37, p<.001)$, cognitive weariness $(t[1762]=5.31, p<.001)$, and emotional exhaustion $(t[1512]=3.46, p<.001)$ were all significantly lower in the current study than pre-pandemic norms; however, 


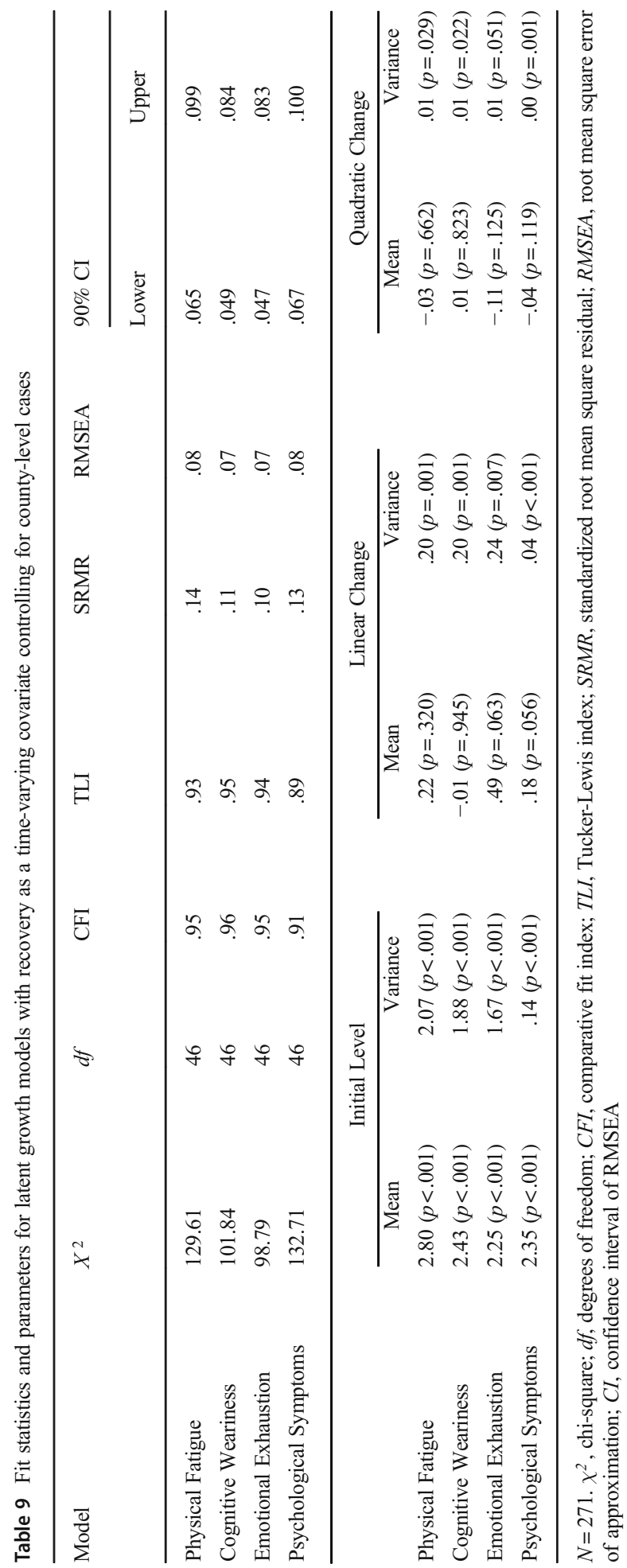


psychological symptoms $(t[1058]=15.70, p<.001)$ were higher than pre-pandemic norms.

Qualitative Recovery Themes We found that both teleworkers and on-site workers frequently engaged in a variety of recovery behaviors to cope with work-related stressors. With $36.0 \%$ of participants mentioning it, relaxation was the most common method of recovery in the present sample, and included examples such as watching television, meditating, sleeping, going outside, and listening to music (e.g., "Mostly I try and relax, take deep breathes [sic], and make sure I get in a walk every day if the weather allows"). At 27.9\%, avoidant thoughts and trying to keep busy was the second most common qualitative theme (e.g., "I leave my work at work and don't think about it when I'm not working"). These attempts to mentally switch off from work represent psychological detachment, whereas keeping busy is a form of control during leisure time (Sonnentag \& Bayer, 2005). At 15.3\%, mastery experiences were a third form of coping with work stressors, in which they attempt to learn a new skill or pick up a new hobby (e.g., "I just try to learn new skills [programming]"). Thus, similar to our quantitative data, these results suggest that engaging in recovery behaviors plays a role in reducing cognitive weariness and improving psychological health during the pandemic. ${ }^{4}$

\section{Discussion}

The COVID-19 pandemic poses one of the greatest global crises in modern history. The CDC warns that stress during an infectious disease outbreak can cause outcomes such as difficulty concentrating, anxiety, and worsening of psychological health symptoms (CDC, 2020). Rooted in stress-reaction versus adaptation models, our results found that participants experienced a decrease is both cognitive weariness and psychological symptoms over time, and this change in respondents' psychological symptoms decelerated over time. It is important to note that these significant changes occurred controlling for county-level COVID-19 cases, which were surprisingly unrelated to all forms of job-related burnout and psychological symptoms. Not only do these results provide support for the adaptation perspective as an explanation to the stressor-strain

\footnotetext{
${ }^{4}$ Our top coping with work-related stressors themes were avoid thinking about stress/keep busy $(27.9 \%)$, going outside (e.g., on walks, playing with kids, gardening; 19.8\%), breathing exercises/meditation (11.7\%), exercise $(9.0 \%)$, spend more time with family $(7.2 \%)$, learning new hobbies/things $(6.3 \%)$, listening to music (4.5\%), and watching television (e.g., Netflix, movies; 4.5\%). In total, these themes made up $91.0 \%$ of all qualitative comments. From this, we coded relaxation as our most common theme at $36.0 \%$, consisting of going outside, breathing exercises/mediation, listening to music, and watching television. Next was avoid thinking about stress/keep busy at $27.9 \%$, which indicate both psychological detachment and control during leisure time. It is not surprising that these two recovery behaviors overlapped considering "control can be described as a person's ability to choose an action from two or more options...focus(ing) on the degree to which a person can decide which activity to pursue during leisure time, as well as when and how to pursue this activity" (Sonnentag \& Fritz, 2007, pp. 206-207). This was followed by mastery behaviors representing $15.3 \%$ of all comments. Following examples from Sonnentag and Fritz (2007), this consisted of exercise and learning new hobbies/things. The only top theme outside of the traditional recovery behaviors was spending more time with family at $7.2 \%$, which may be a pandemic-specific form of recovery given the increased time people are spending at home during "safer at home" or "shelter-in-place" orders.
} 
response, but given the psychological salience of the pandemic spread across the US during data collection, the experimental realism for such theory testing is extremely high and rare in practice.

We did not observe significant change in physical fatigue for the overall sample, though we did find that on-site workers experienced significant increases in physical fatigue, although these negative effects decelerated over time. This provides support for the stress-reaction perspective. Interestingly, we found initial level differences for participants engaged in only telework or on-site work-teleworkers experience lower emotional exhaustion at initial assessment, whereas on-site workers experienced lower cognitive weariness and emotional exhaustion at initial assessment, compared to those who worked varied jobsites (i.e., working both remotely and on-site). These results suggest differences in factors of job-related burnout based on potential job stressors required by teleworkers, on-site workers, and workers in varied jobsites.

Finally, it is important to note that a broad set of recovery behaviors had effects on linear and quadratic change for cognitive weariness and psychological symptoms among all workers. This is important as all forms of recovery behaviors help workers lessen stressors and improve strain produced by COVID-19. We also found that no form of recovery behaviors we examined helped relieve physical fatigue experienced by on-site workers.

\section{Theoretical and Practical Implications}

The present study has several noteworthy implications for both theory and practice. This research, for example, provides fundamental insights into how workers adapt during a global crisis. Overall, our findings suggest that workers are highly resilient. First, they appear to be largely unaffected by county-level infection rates. Indeed, we observed not a single instance in which county-level cases were related to either jobrelated burnout or psychological symptoms (see Table 1). Second, we found that our participants' levels of job-related burnout were significantly lower than pre-pandemic norms. This may suggest that psychological health is a priority to workers during the onset of a pandemic and job-related strain is psychologically less salient. Finally, supporting the adaptation model, exposure to COVID-19 stressors resulted in a general decrease in cognitive weariness and psychological symptoms over time.

Although adaptive processes may produce some beneficial effects (e.g., they may buffer the effects of prolonged exposure to pandemic-related stressors on employee strains), they may also produce some negative effects. Adaptive processes, for example, may cause workers to ignore the pandemic-related risks that are present within their workplaces, thus causing them to lapse in their compliance with protective guidelines (e.g., wearing masks, practicing social distance, practicing good hand hygiene). Organizations, therefore, should take steps to minimize this negative side effect of adaptation. Such efforts could include establishing clear policies about protective behaviors and regularly reminding workers of those policies.

Another theoretical implication involves our findings for the adaptation perspective for cognitive and psychological forms of strain and the stress-reaction perspective for physical strain. That is, although the entire sample displayed adaptation towards cognitive weariness and psychological symptoms over time, on-site workers displayed different patterns of strain for physical fatigue. Specifically, on-site workers 
experienced an increase in physical fatigue over time, thus supporting the stressreaction perspective. As such, our results support both the stress-reaction and adaptation perspectives, and highlight how each theoretical approach may be conditional based on the stressor-strain combination.

For practice, the finding that on-site workers displayed strains over the course of our study that differ from those of remote workers suggests that different approaches should be taken to mitigate job strain for these groups. Specifically, given that onsite workers exhibited higher rates of physical fatigue over time, organizations employing essential, frontline, or general on-site workers should address the depletion of workers' physical resources. Some ways in which the physical component of burnout can be addressed for on-site workers include restricting working hours, limiting shift lengths, avoiding understaffing, and providing organizational support for employees (Hamama, 2012; Shirom et al., 2010; Stimpfel et al., 2012). Additionally, employers should allow on-site workers to do aspects of their jobs remotely whenever possible.

Finally, all four recovery behaviors were related to significant change in well-being over time. This suggests that recovery behaviors are effective for remedying the negative psychological effects of a pandemic, such as cognitive weariness and psychological symptoms. Sonnentag et al. (2017) noted that there is promising evidence that recovery behaviors can be trained through interventions focused around stress reduction or mindfulness training. Our results provide evidence that suggests increases in recovery behaviors should translate into improved well-being. Accordingly, employers should inform their employees of the importance of recovery behaviors during these stressful times and take steps to increase employee recovery. Furthermore, recovery behaviors are easily scalable in the context of a pandemic - compared with many other interventions, they are relatively easy to deliver remotely.

\section{Limitations and Future Research}

One potential limitation in this study is the timeframe and duration in which data were collected. As the pandemic developed in the US, our team attempted to move quickly to collect these data and test our study hypotheses. Though we did move quickly from a University-governed scientific research perspective, many events unfolded between the time that this study was conceived and when data collection began (e.g., National Emergencies Act on March 13, 2020; state mandated stay-at-home orders prior to April 1, 2020). As such, it would have been beneficial from a latent growth modeling perspective to collect data as soon as the outbreak started in the US, as well as continue collecting data as the US "reopened." Such data would have allowed us to further model the within-person trajectories of job-related burnout and psychological symptoms throughout the development, closing, and reopening of the US during the pandemic. This would allow for better estimation of ceiling and floor effects in burnout, psychological symptoms, and other strain-based outcomes inherent in stress-reaction and adaptation models during the pandemic. Future research would benefit from studying stress-reaction and adaptation models with longer pre- and post-crisis timelines.

Because all study variables other than county-level cases were measured using a common method, which was our statistical control, results can be susceptible to 
common method variance (CMV; Podsakoff et al., 2003). However, this should not be a major limitation for several reasons. First, self-reports are the most direct and dependable means of assessing job-related burnout and psychological health, and other methods would have questionable construct validity given these are internal psychological states. Second, considering LGM estimates growth trajectories within-person over time, and a common statistical approach to address CMV uses "repeated measure designs with within-person centering as a way of controlling individuals' response tendencies across multiple observations" (Simmering et al., 2015, p. 506), this concern should be mitigated. Finally, because CMV is unlikely to produce artifactual interactions (Evans, 1985; Siemsen et al., 2010), it is unlikely that our findings were affected by CMV. Nonetheless, future research would benefit from the inclusion of objective measures of criteria, such as those provided by cortisol levels and physiological measures of strain, when studying stress-reaction and adaptation models.

Among the results that we observed, a number of the significant coefficients were small, and a number of the coefficients were nonsignificant. Still, we believe the observed results are meaningful when taken as a whole because they speak to the ways in which pandemic stressors have different effects on worker well-being based on the type of well-being that is investigated and the location at which respondents work. We encourage future research to continue the important task of investigating multiple specific types of well-being outcomes and worker locations in order to identify those which are most impacted by pandemic-related stressors, as well as how recovery behaviors can assuage these impacts.

\section{Conclusion}

Supporting the adaptation perspective, our results found that cognitive weariness and psychological symptoms both decreased over time, and this decrease decelerated over time. Supporting the stress-reaction perspective, we also found that on-site workers experienced increased physical fatigue over time, and that this fatigue also decelerated over time. These results illuminate how stressor-strain relationships are contingent on the variables examined, such that cognitive and psychological strains appear to follow an adaptation perspective whereas physical strains appear to follow a stress-reaction perspective. A final discovery was that recovery behaviors accounted for linear and quadratic growth terms in cognitive weariness and psychological symptoms for the full sample, but not physical fatigue for on-site workers. Given the surge in COVID-19 in the US during the time of this study, as well as the pervasiveness and salience of the pandemic, these results provide support for the core principles underlying both stressreaction and adaptation models and have theoretical and practical implication within the context of the pandemic and beyond.

\section{Declarations}

Conflict of Interest On behalf of all authors, the corresponding author states that the authors have NO affiliations with or involvement in any organization or entity with any financial interest (such as honoraria; educational grants; participation in speakers' bureaus; membership, employment, consultancies, stock ownership, or other equity interest; and expert testimony or patent-licensing arrangements), or non-financial interest (such as personal or professional relationships, affiliations, knowledge or beliefs) in the subject matter or materials discussed in this manuscript. 


\section{References}

Baethge, A., Vahle-Hinz, T., \& Rigotti, T. (2020). Coworker support and its relationship to allostasis during a workday: A diary study on trajectories of heart rate variability during work. Journal of Applied Psychology, 105(5), 506-526. https://doi.org/10.1037/ap10000445.

Bakker, A. B., \& Demerouti, E. (2007). The job demands-resources model: State of the art. Journal of Managerial Psychology, 22(3), 309-328. https://doi.org/10.1108/02683940710733115.

Bakker, A. B., \& Demerouti, E. (2014). Job demands-resources theory. In C. Cooper \& P. Chen (Eds.), Wellbeing: A complete reference guide (pp. 37-64). Wiley-Blackwell. https://doi.org/10.1002/ 9781118539415 .wbwell019.

Barber, L. K., \& Santuzzi, A. M. (2015). Please respond ASAP: Workplace telepressure and employee recovery. Journal of Occupational Health Psychology, 20(2), 172-189. https://doi.org/10.1037/ a0038278.

Behrend, T. S., Sharek, D. J., Meade, A. W., \& Wiebe, E. N. (2011). The viability of crowdsourcing for survey research. Behavior Research Methods, 43, 800-813. https://doi.org/10.3758/s13428-011-0081-0.

Bennett, A. A., Bakker, A. B., \& Field, J. G. (2017). Recovery from work-related effort: A meta-analysis. Journal of Organizational Behavior, 39(3), 262-275. https://doi.org/10.1002/job.2217.

Bowling, N. A., \& Beehr, T. A. (2016). Opponent process theory can help explain some effects of resilience. Industrial and Organizational Psychology, 9(2), 486-490. https://doi.org/10.1017/iop.2016.44.

Bowling, N. A., Beehr, T. A., Wagner, S. H., \& Libkuman, T. M. (2005). Adaptation-level theory, opponent process theory, and dispositions: An integrated approach to the stability of job satisfaction. Journal of Applied Psychology, 90(6), 1044-1053. https://doi.org/10.1037/0021-9010.90.6.1044.

Buhrmester, M., Kwang, T., \& Gosling, S. (2011). Amazon's mechanical Turk a new source of inexpensive, yet high-quality, data? Perspectives on Psychological Science, 6(1), 3-5. https://doi.org/10.1177/ 1745691610393980.

Bureau of Labor Statistics. (May 2020). The employment situation - April 2020. Department of Labor, United States of America. USDL-20-0815.

Carver, C. S., Scheier, M. F., \& Weintraub, J. K. (1989). Assessing coping strategies: A theoretically based approach. Journal of Personality and Social Psychology, 56(2), 267-283. https://doi.org/10.1037/00223514.56.2.267.

Centers for Disease Control and Prevention (CDC; 2020, July 1). Coronavirus Disease 2019 (COVID-19): Coping with Stress. Retrieved from https:/www.cdc.gov/coronavirus/2019-ncov/daily-life-coping/ managing-stress-anxiety.html

Chopik, W. J. (2015). Relational attachment and ethical workplace decisions: The mediating role of emotional burnout. Personality and Individual Differences, 75, 160-164. https://doi.org/10.1016/j.paid.2014.11. 007.

Chung, A. Y. (2016). Coping strategies and its moderating effect on the relationship between perfectionism and burnout and fatigue (Doctoral dissertation, Roosevelt University).

Delanoeije, J., Verbruggen, M., \& Germeys, L. (2019). Boundary role transitions: A day-to-day approach to explain the effects of home-based telework on work-to-home conflict and home-to-work conflict. Human Relations, 72(12), 1843-1868. https://doi.org/10.1177/0018726718823071.

Diener, E., Lucas, R. E., \& Scollon, C. N. (2006). Beyond the hedonic treadmill: Revising the adaptation theory of well-being. American Psychologist, 61(4), 305-314. https://doi.org/10.1037/0003-066X.61.4. 305 .

Dong, E., Du, H., \& Gardner, L. (2020). An interactive web-based dashboard to track COVID-19 in real time. The Lancet Infectious Diseases, 20(5), 533-534. https://doi.org/10.1016/S1473-3099(20)30120-1.

Duncan, T. E., Duncan, S. C., \& Strycker, L. A. (2013). An introduction to latent variable growth curve modeling: Concepts, issues, and application. Routledge Academic.

Early, R. J. (2013). Using objective measures to capture work-family conflict. (Master's Thesis, Wayne State University).

Evans, M. G. (1985). A Monte Carlo study of the effects of correlated method variance in moderated multiple regression analysis. Organizational Behavior and Human Decision Processes, 36(3), 305-323. https:// doi.org/10.1016/0749-5978(85)90002-0.

Gajendran, R. S., \& Harrison, D. A. (2007). The good, the bad, and the unknown about telecommuting: Metaanalysis of psychological mediators and individual consequences. Journal of Applied Psychology, 92(6), 1524-1541. https://doi.org/10.1037/0021-9010.92.6.1524. 
Gerber, M., Colledge, F., Mücke, M., Schilling, R., Brand, S., \& Ludyga, S. (2018). Psychometric properties of the Shirom-Melamed burnout measure (SMBM) among adolescents: Results from three cross-sectional studies. BMC Psychiatry, 18(1), 1-13. https://doi.org/10.1186/s12888-018-1841-5.

Goldberg, D. (1978). Manual of the general health questionnaire. NFER-Nelson.

Grimm, K. J., Ram, N., \& Estabrook, R. (2017). Growth modeling: Structural equation and multilevel modeling approaches. Guilford Publications.

Gummer, T., Roßmann, J., \& Silber, H. (2018). Using instructed response items as attention checks in web surveys: Properties and implementation. Sociological Methods \& Research, 1-27. https://doi.org/10.1177/ 0049124118769083.

Hamama, L. (2012). Burnout in social workers treating children as related to demographic characteristics, work environment, and social support. Social Work Research, 36(2), 113-125. https://doi.org/10.1093/ swr/svs003.

Hobfoll, S. E. (1989). Conservation of resources: A new attempt at conceptualizing stress. American Psychologist, 44(3), 513-524.

Huang, J. L., Liu, M., \& Bowling, N. A. (2015). Insufficient effort responding: Examining an insidious confound in survey data. Journal of Applied Psychology, 100(3), 828-845. https://doi.org/10.1037/a0038510.

Hudson, C. K., \& Shen, W. (2018). Consequences of work group manpower and expertise understaffing: A multilevel approach. Journal of Occupational Health Psychology, 23(1), 85-98. https://doi.org/10.1037/ ocp0000052.

Kim, E. S., \& Willson, V. L. (2014). Measurement invariance across groups in latent growth modeling. Structural Equation Modeling: A Multidisciplinary Journal, 21(3), 408-424. https://doi.org/10.1080/ 10705511.2014.915374.

LePine, J. A., Podsakoff, N. P., \& LePine, M. A. (2005). A meta-analytic test of the challenge stressorhindrance stressor framework: An explanation for inconsistent relationships among stressors and performance. Academy of Management Journal, 48(5), 764-775. https://doi.org/10.5465/amj.2005.18803921.

Litman, L., Robinson, J., \& Abberbock, T. (2017). TurkPrime. com: A versatile crowdsourcing data acquisition platform for the behavioral sciences. Behavior Research Methods, 49(2), 433-442. https:// doi.org/10.3758/s13428-016-0727-z.

Lucas, R. E. (2005). Time does not heal all wounds: A longitudinal study of reaction and adaptation to divorce. Psychological Science, 16(12), 945-950. https://doi.org/10.1111/j.1467-9280.2005.01642.x.

Lucas, R. E., Clark, A. E., Georgellis, Y., \& Diener, E. (2004). Unemployment alters the set point for life satisfaction. Psychological Science, 15(1), 8-13. https://doi.org/10.1111/j.0963-7214.2004.01501002.x.

Lundgren-Nilsson, Å., Jonsdottir, I. H., Pallant, J., \& Ahlborg, G. (2012). Internal construct validity of the Shirom-Melamed burnout questionnaire (SMBQ). BMC Public Health, 12(1), 1-8. https://doi.org/10. 1186/1471-2458-12-1.

McGonagle, A. K., Huang, J. L., \& Walsh, B. M. (2016). Insufficient effort survey responding: An underappreciated problem in work and organisational health psychology research. Applied Psychology, 65(2), 287-321. https://doi.org/10.1111/apps.12058.

Meade, A. W., \& Craig, S. B. (2012). Identifying careless responses in survey data. Psychological Methods, 17(3), 437-455. https://doi.org/10.1037/a0028085.

Michel, J. S., O’Neill, S. K., Hartman, P., \& Lorys, A. (2018). Amazon's mechanical Turk as a viable source for organizational and occupational health research. Occupational Health Science, 2(1), 83-98. https:// doi.org/10.1007/s41542-017-0009-x.

Muthén, L. K., \& Muthen, B. (2017). Mplus user's guide: Statistical analysis with latent variables, user's guide. Muthén \& Muthén.

Peer, E., Vosgerau, J., \& Acquisti, A. (2014). Reputation as a sufficient condition for data quality on Amazon mechanical Turk. Behavior Research Methods, 46(4), 1023-1031. https://doi.org/10.3758/s13428-013-0434-y.

Podsakoff, P. M., MacKenzie, S. B., Lee, J. Y., \& Podsakoff, N. P. (2003). Common method biases in behavioral research: A critical review of the literature and recommended remedies. Journal of Applied Psychology, 88(5), 879-903. https://doi.org/10.1037/0021-9010.88.5.879.

Preacher, K. J., Wichman, A. L., MacCallum, R. C., \& Briggs, N. E. (2008). Latent growth curve modeling (no. 157). Sage.

Putnick, D. L., \& Bornstein, M. H. (2016). Measurement invariance conventions and reporting: The state of the art and future directions for psychological research. Developmental Review, 41, 71-90. https://doi.org/ 10.1016/j.dr.2016.06.004.

Rudolph, C.W., Allan, B., Clark, M., Hertel, G., Hirschi, A., Kunze, F., Shockley, K., Shoss, M., Sonnentag, S., \& Zacher, H. (2020). Pandemics: Implications for research and practice in industrial and organizational psychology. Industrial and Organizational Psychology: Perspectives on Science and Practice. 
Santuzzi, A. M., \& Barber, L. K. (2018). Workplace telepressure and worker well-being: The intervening role of psychological detachment. Occupational Health Science, 2(4), 337-363. https://doi.org/10.1007/ s41542-018-0022-8.

Schaufeli, W. B., Bakker, A. B., \& Van Rhenen, W. (2009). How changes in job demands and resources predict burnout, work engagement, and sickness absenteeism. Journal of Organizational Behavior, 30(7), 893-917. https://doi.org/10.1002/job.595.

Schilling, R., Colledge, F., Brand, S., Ludyga, S., \& Gerber, M. (2019). Psychometric properties and convergent validity of the Shirom-Melamed burnout measure in two German-speaking samples of adult workers and police officers. Frontiers in Psychiatry, 10, 536. https://doi.org/10.3389/fpsyt.2019.00536.

Schleider, J. L., \& Weisz, J. R. (2015). Using mechanical Turk to study family processes and youth mental health: A test of feasibility. Journal of Child and Family Studies, 24(11), 3235-3246. https://doi.org/10. 1007/s10826-015-0126-6.

Shirom, A., \& Melamed, S. (2006). A comparison of the construct validity of two burnout measures in two groups of professionals. International Journal of Stress Management, 13(2), 176-200. https://doi.org/10. 1037/1072-5245.13.2.176.

Shirom, A., Nirel, N., \& Vinokur, A. D. (2010). Work hours and caseload as predictors of physician burnout: The mediating effects by perceived workload and by autonomy. Applied Psychology, 59(4), 539-565. https://doi.org/10.1111/j.1464-0597.2009.00411.x.

Siemsen, E., Roth, A., \& Oliveira, P. (2010). Common method bias in regression models with linear, quadratic, and interaction effects. Organizational Research Methods, 13(3), 456-476. https://doi.org/10. $1177 / 1094428109351241$.

Simmering, M. J., Fuller, C. M., Richardson, H. A., Ocal, Y., \& Atinc, G. M. (2015). Marker variable choice, reporting, and interpretation in the detection of common method variance: A review and demonstration. Organizational Research Methods, 18(3), 473-511. https://doi.org/10.1177/1094428114560023.

Sinclair, R., Allen, T., Barber, L., Bergman, M., Britt, T., Butler, A., Ford, M., Hammer, L., Kath, L., Probst, T., \& Yuan, Z. (2020). Occupational health science in the time of COVID-19: Now more than ever. Occupational Health Science. https://doi.org/10.1007/s41542-020-00064-3.

Sonnentag, S., \& Bayer, U. V. (2005). Switching off mentally: Predictors and consequences of psychological detachment from work during off-job time. Journal of Occupational Health Psychology, 10(4), 393-414. https://doi.org/10.1037/1076-8998.10.4.393.

Sonnentag, S., \& Fritz, C. (2007). The recovery experience questionnaire: Development and validation of a measure for assessing recuperation and unwinding from work. Journal of Occupational Health Psychology, 12(3), 204-221. https://doi.org/10.1037/1076-8998.12.3.204.

Sonnentag, S., Venz, L., \& Casper, A. (2017). Advances in recovery research: What have we learned? What should be done next? Journal of Occupational Health Psychology, 22(3), 365-380. https://doi.org/10. 1037/ocp0000079.

Sprouse, J. (2011). A validation of Amazon mechanical Turk for the collection of acceptability judgments in linguistic theory. Behavior Research Methods, 43(1), 155-167. https://doi.org/10.3758/s13428-010-0039-7.

Stimpfel, A. W., Sloane, D. M., \& Aiken, L. H. (2012). The longer the shifts for hospital nurses, the higher the levels of burnout and patient dissatisfaction. Health Affairs, 31(11), 2501-2509. https://doi.org/10.1377/ hlthaff.2011.1377.

Tarabay, C. (2015). Short- and long-term cumulative risk effects on aggression (Master's Thesis, Macquarie University).

Vandenberg, R. J., \& Morelli, N. A. (2016). A contemporary update on testing for measurement equivalence and invariance. In J. P. Meyer (Ed.), Handbook of Employee Commitment (pp. 449-461). Edward Elgar Publishing. https://doi.org/10.4337/9781784711740.00047.

Varghese, L. S., Rogers, A. P., Finkelstein, L., \& Barber, L. K. (2020) Examining mentors as buffers of burnout for employees high in neuroticism. Human Resource Development Quarterly. https://doi.org/10. 1002/hrdq. 21390.

Walter, S. L., Seibert, S. E., Goering, D., \& O’Boyle Jr., E. H. (2019). A tale of two sample sources: Do results from online panel data and conventional data converge? Journal of Business and Psychology, 34, 425452. https://doi.org/10.1007/s10869-018-9552-y.

Wilkes, S. M., Barber, L. K., \& Rogers, A. P. (2018). Development and validation of the workplace interruptions measure. Stress and Health, 34(1), 102-114. https://doi.org/10.1002/smi.2765.

World Health Organization (WHO; 2020, March 11). WHO director-General's opening remarks at the media briefing on COVID-19. World Health Organization. Retrieved from https:/www.who.int/dg/speeches/detail/whodirector-general-s-opening-remarks-at-the-media-briefingon-covid-19\%2D\%2D-11-march-2020 
Yarrish, C., Groshon, L., Mitchell, D., Appelbaum, A., Klock, S., Winternitz, T., \& Friedman-Wheeler, G. (2019). Finding the signal in the noise: Minimizing responses from bots and inattentive humans in online research. The Behavior Therapist, 42(7), 235-242.

Publisher's Note Springer Nature remains neutral with regard to jurisdictional claims in published maps and institutional affiliations. 